\title{
DIFERENTES FORMAS DE ESTAR NA FESTA
}

\author{
Tereza Caroline Lôbo (UFG) \\ Carlos Eduardo Santos Maia (UFJF)
}

Este artigo propõe refletir sobre as festas, entendidas como lugar de interações específicas e de multiplicidade de trajetórias. Busca-se identificar as diferentes formas de estar na festa; por isso, tomam-se à guisa de ponto de partida os rituais e os modos como os partícipes se colocam dentro da festa de Sant'Ana na Capela do Rio do Peixe, atribuindo-Ihe valores significativos.

FESTA, LUGAR, PIRENÓPOLIS, CAPELA DO RIO DO PEIXE. 


\section{INTRODUÇÃO}

O festejo em louvor a Nossa Senhora Sant'Ana ocorre desde o século XVIII, em juIho, no povoado da Capela do Rio do Peixe, em Pirenópolis, GO, sendo conhecido como festa da Capela e incluindo manifestações ritualísticas em homenagem à avó de Cristo: comer, beber, rezar e festejar simultaneamente. A romaria até o local da festa, os terços e as celebrações homenageando os santos de devoção, ${ }^{1}$ a folia,

1. Além de Sant'Ana, a Imaculada Conceição e São Sebastião são santos homenageados com terços, rezas, cânticos, fogueiras e mastros. as comemorações festivas nos acampamentos e nos ranchos improvisados como boates dão estrutura à festividade e moldam as experiências individuais e sociais com um lugar, carregando-o de simbologias, sentidos e conceitos. Propomos, neste artigo, investigação que destaque, via alguns rituais, os significados da composição festa-lugar.

Resgatemos de início as três propriedades que definem lugar, segundo Relph (1980), quais sejam: a paisagem, a localização e o envolvimento pessoal. O autor privilegia o envolvimento pessoal, pelo fato de só ele definir a experiência com o lugar. Assim a imagem do espaço é socialmente constituída, estando associada à identidade, podendose compreendê-la através do indivíduo, da comunidade e do compartilhamento das identidades do e com o lugar. Desse modo, quanto mais interno é o envolvimento com o lugar, maior a identificação; já a 'deslugaridade' ocorre quando há a perda do sentido de lugar. Durante os festejos, como veremos, procuramos identificar a composição do lugar a partir desse envolvimento pessoal mencionado por Relph e buscar respostas para alguns questionamentos, como, por exemplo: como ocorrem as diversas participações nos rituais que dão sentido à festividade? o que esse envolvimento pessoal implica ao situarse em co-presença (com os outros participantes e com o sagrado)?

Dito isso, cabe destacar o fato de que, ao examinar as formas de participação nesse festejo, procuramos analisar o alcance e a estrutura da festa, partindo (pretensiosamente) como Geertz (1989) de uma antropologia interpretativa e simbólica, examinando os pequenos detalhes da festividade identificados nos depoimentos e nas conversas com romeiros, na ideia de uma cultura microscópica. Ao observar a dinâmica da festa de Sant'Ana, com foco nos momentos compartilhados e nitidamente implicados com o envolvimento pessoal, descobrimos estrutura que compõe a festividade atribuindo-lhe uma imagem espacial, ou melhor, um conceito de lugar, fundamental para a compreensão da cultura e das identidades aí constituídas.

É instigante identificar, na gama de maneiras de se envolver e participar dos festejos, as diferentes formas de estar na festa. Por isso o ponto de partida foi centrado em determinados rituais da festa de Sant'Ana, indicadores de como o fazer-se presente na festa é estar envolvido em emoções, de modo que as ações ritualísticas tenham as dimensões social e simbólica articuladas para atribuir sentido à realidade e à compreensão do mundo circundante, bem como à vida e ao imaginário das pessoas ligadas aos festejos. 


\section{"ASSIM FIZERAM OS DEUSES; ASSIM FAZEM OS HOMENS"}

Esse provérbio indiano é a síntese da teoria que fundamenta os rituais em todos os lugares, consoante Eliade (1992), que parte do estudo de aspectos da ontologia arcaica capazes de ser identificados no comportamento dos homens das sociedades tradicionais - os deuses, os heróis civilizadores e os ancestrais míticos seriam os inspiradores de todos os atos religiosos. Ao propor um estudo da história da religião com foco na estrutura do simbolismo religioso, o autor considera que "os símbolos e os mitos vêm de longe: eles fazem parte do ser humano, e é impossível não os reencontrar em qualquer situação existencial do homem no Cosmo" (ELIADE, 2002, p. 21). Os fenômenos religiosos, pelo fato de se manifestarem e revelarem a nós, "são cunhados como uma medalha pelo momento histórico que os viu nascer. Não existe fato religioso 'puro', fora da história, fora do tempo. A mais nobre mensagem religiosa, a mais universal experiência mística, o mais comum dos comportamentos humanos - como, por exemplo, o temor religioso, o rito, a prece - singularizam-se e delimitam-se à medida que se manifestam" (ELIADE, 2002, p. 27-28).

Seguindo essas diretrizes, vejamos algumas formas de manifestação do comportamento humano na festa, em especial na festa de Sant'Ana no povoado da Capela do Rio do Peixe. Atentemos para o fato de que a perspectiva experiencial humana é bastante fluida, sobretudo em se tratando do sagrado, já que as pessoas constituem aí realidade de mundo de maneira distinta, ou seja, "O comportamento do romeiro no espaço sagrado consiste em dar qualidade nova ao que é declarado, desejado e consagrado. Espera-se a mudança das coisas profanas para a esfera do sagrado. Assim é possível reconhecer atos religiosos e práticas religiosas" (ROSENDAHL, 1997, p. 137).

Embora reconheçamos esses atos e práticas religiosas, as vivências da festa, os modos de vivenciá-la e suas interpretações são múltiplos e variáveis conforme a intensidade de envolvimento, implicando às vezes "estados embaraçados" (MAIA, 2010). À medida que a festa vai adquirindo definição e significado para quem dela participa, ela não só está em como é um lugar carregado de simbologias, sentidos e conceitos. Temos ciência de que a fluidez experiencial humana e seus significados impossibilitam interpretação exata do fenômeno - bem como encontrar o real significado da festa de Sant'Ana para cada participante, grupo ou mesmo instituição envolvidos nos vários momentos do evento; nem temos, aliás, tal pretensão utópica.

No estudo das imagens e dos símbolos, Eliade (2002, p. 20) reconhece que "o problema central e mais árduo continua sendo, evidentemente, o da interpretação". Ao discutir a validade da hermenêutica, o autor assegura ser possível demonstrar com exemplos o que "quer dizer" cada símbolo; assim, utilizando o exemplo do "Centro", argumenta que

a validade do símbolo como forma de conhecimento não depende do grau de compreensão de tal ou tal indivíduo. Textos e monumentos figurados nos provam abundantemente que, pelo menos para certos indivíduos de uma sociedade arcaica, o simbolismo do 'Centro' era transparente na sua totalidade, o 
resto da sociedade contentava-se em 'participar' do simbolismo. E, aliás, é difícil precisar os limites de tal participação: ela varia em função de um número indeterminado de fatores. Tudo o que podemos dizer é que a atualização de um símbolo não é mecânica: ela está relacionada às tensões e às mudanças da vida social, e em último lugar, aos ritmos cósmicos (ELIADE, 2002, p. 21).

As festas de romaria configuram momentos de integração e interação de caráter político, religioso e simbólico, nos quais diferentes segmentos sociais podem reafirmar seus laços de solidariedade ou não, gerando tensões. Cada partícipe traz consigo internalizado os motivos de sua participação, amplamente variáveis e correlacionados com fatores diversos, produzindo as ações e reações próprias das atuações e inter-relações, costurando o tecido que compõe o evento. As várias formas de participação que definem as identidades do lugar podem, segundo Relph (1980), ser consideradas por intermédio da experiência da 'internidade' (insideness) em oposição à de 'externidade' (outsideness), ou seja, quanto mais profundo é o envolvimento com a festa, mais forte é a identidade com o lugar.

Nesse momento, configuram-se os atritos comuns entre os que vivenciam a essência da festa pela experiência de "internidade" em oposição aos que a vivenciam como 'externidade'. As atitudes geradas a partir das experiências impulsionam as diferentes relações entre os participantes e o festejo em questão, e produzem expressões distinta quanto à (res)significação, (re)criação e (re)apropriação da manifestação festiva. Daí as várias formas de participação e graus de envolvimento que vão

2. "To be inside a place is to belong to it and to identify with it, and the more profoundly inside you are the stronger is this identity with the place". estabelecer níveis de 'internidade'/'externidade' com base nos tipos de identidade com o lugar. Conforme varia a intensidade de participação no festejo, variam também os limites entre interno e externo, pois "estar no lugar é pertencer a ele e identificarse com ele; quanto mais profundamente se insere, mais forte é a identidade com o lugar" (RELPH, 1980, p. 49). ${ }^{2}$

A presença, o estar participando, "possui um caráter de direcionamento" (HEIDEGGER, 2009). As direções ora se aproximarão da representação real da festa, o que ela significou e significa para os membros participantes, ora se afastarão rumo ao ideal, quando, por exemplo, da falta de algum aspecto. O que indica o norte dentro da região a ser ocupada são os sinais, os objetos ritualísticos que, como instrumentos, apontam a direção, mantendo aberto, na circunvisão, o destino do pertencer. Importa lembrar que a aproximação ou não da qualidade do que se vivencia (o direcionamento) é conduzida como modo de ser-no-mundo. O mais importante não é a quantidade dos aspectos vivenciados, mas a qualidade de estar junto do que se espera vivenciar, ou seja, o ser-nomundo em co-presença.

Em nossas reflexões, interrogamos os integrantes do festejo em seu lugar de atuação. As questões abordadas durante as entrevistas, na maioria das vezes, surgiram no momento em que os partícipes estavam vivenciando a festa e, portanto, são depoimentos carregados de emoção. Acerca desse sentimento, concordamos com Maia quando afirma que "as emoções, num plano ôntico, são motivadoras do comportamento ritua- 
lístico, definindo tanto os gestos e as ações quanto, numa perspectiva mais ampla, o dito e o não dito nos rituais, pois muito do que se mostra nos rituais se faz como não dito" (MAIA, 2010, p. 99).

Dessa maneira, empenhamo-nos em valorizar a emoção do participante e os acontecimentos desencadeadores de tal sentimento. A esse respeito, Maia pondera que a emoção ritualística constitui-se também num plano ontológico, pois, "nos rituais, mais do que em outras instâncias da existência humana, as emoções são fundantes, incontornáveis e alteram a qualidade do mundo (2010, p. 102).

\section{OS HOMENS QUE FAZEM A FESTA}

A vinculação do partícipe com a festa é constituída à proporção que os sujeitos se vão envolvendo com os campos de atuação reconhecidos pelos que dela participam. Mas não é tão simples conseguir um espaço de atuação que seja reconhecido pelos partícipes; isso pode levar anos e até nem acontecer, ou seja, para ser um romeiro tradicional, é preciso frequentar a festa com regularidade, integrar-se a sua rede de organização, nela atuar e conquistar o reconhecimento de seus grupos estruturantes; em outras palavras, é preciso habitar, por meio da interação, o espaço-tempo da festa. Isso vale, outrossim, para os moradores do lugar, pois nem todos carregam autoridade suficiente para agir de forma significativa na estruturação da festa. Uma das formas de participar dos festejos é assumir algum cargo dos vários rituais, submetendo-se aos sorteios para festeiro, rainha, mordomos e alferes da folia de Sant'Ana.

Analisamos a seguir a atuação de um partícipe tradicional do lugar, funcionário público federal aposentado que vive no povoado da Capela do Rio do Peixe desde que ficou viúvo, há pouco mais de dez anos. Descende de antiga família habitante da região das Contendas, há aproximadamente $30 \mathrm{~km}$ da Capela do Rio do Peixe, com tradição de participação nos festejos de Sant'Ana.

O depoente contou-nos que a Capela sempre o atraiu por ser lugar de devoção de sua falecida mãe e, assim que pôde, comprou uma casa para frequentar o povoado nos períodos das festividades. Após a viuvez, deixou os filhos em Brasília e foi viver sozinho na pequena comunidade do Rio do Peixe. Durante a festa, a casa fica pequena para abrigar sua enorme família, composta por filhos, netos e bisnetos - são os "Fulanos de Sá", um dos vários grupos que frequentam a festa atualmente e são identificados pelo uso de camisetas alusivas à festa e/ou a Sant'Ana. Hoje, o depoente é um importante mantenedor das atividades realizadas na igreja, fora do período da festa de Sant'Ana, e um dos mais ativos arrematadores das prendas dos leilões, como registramos nas festas de São Sebastião, Nossa Senhora de Fátima e Imaculada Conceição. ${ }^{3}$ Em 2008, foi sorteado como alferes da folia de Sant'Ana, sendo responsável pela visibilidade da folia, que ficou vários anos sem girar. Desde quando iniciamos nosso tra-

3. Esses festejos acontecem nos meses de janeiro, maio e dezembro, respectivamente, e apresentam estrutura festiva semelhante: todos têm novenas, rezas de terços e leilões. Diferentemente da festa da Capela, contam apenas com a participação da comunidade do povoado e das fazendas circunvizinhas. 
balho no povoado, ouvíamos falar de sua aspiração a festeiro de Sant'Ana, o que conseguiu em 2010 para realizar a festa de 2011.

Além dele, uma neta foi sorteada para rainha nos festejos de 2010 mas, impossibilitada de receber a coroa, pois já tinha voltado para Brasília quando aconteceu o sorteio, foi representa pela irmã, que se fez passar pela sorteada, sendo até mesmo coroada, rompendo uma tradição, pois é regra instituída nos últimos anos, motivada por desistências ao longo do ciclo festivo de alguns sorteados, repetir-se o sorteio quando o contemplado não se encontra presente. Perguntamos à irmã da rainha sorteada qual era sua relação com a festa e, fazendo-se passar pela rainha, ela respondeu: "é uma relação já de muitos anos, porque meus avós são daqui, minha mãe nas-

4. Romeira da festa da Capela. Entrevista realizada na Capela do Rio do Peixe em 26.7.2009. ceu aqui em Pirenópolis. Então, desde pequena nós vimos para a festa". ${ }^{4}$ A depoente estava visivelmente emocionada com o fato de realizar um desejo do avô - que, há anos, estava na sorte para festeiro - e, ao mesmo tempo, receosa com a reação dos partícipes diante do fato de ela substituir a irmã. No ano seguinte, a rainha estendeu faixas pelo povoado com frases de agradecimento à comunidade pela ajuda prestada na organização da festa. Todos esses fatos que acompanhamos em nossa pesquisa de campo fizeram-nos notar o quanto é complexo o emaranhado de acontecimentos que se vão formando em torno das relações sociais que são constituídas para a realização da festa.

A despeito da efemeridade, da singularidade do evento e da experiência individual e única que a devoção proporciona, seus rituais são até certo ponto previsíveis e balizados pela coletividade. A questão fundamental que se traz à baila é saber como uma experiência fenomenológica, uma festa tradicional de devoção a um santo - Nossa Senhora Sant'Ana -, com seus rituais, cria espaços de apropriação pelos que dela participam e dão sentido a sua existência no presente. Nos casos descritos, entendemos que o depoente e sua família, representada pelas netas, entraram nos sorteios e atuaram e atuam - de forma direta na manutenção das tradições da festa, sendo reconhecidos pela comunidade e tendo compreensão do papel que precisam desempenhar nos rituais da festa. Era fato conhecido por todos no povoado e pelos romeiros mais envolvidos na organização o desejo do entrevistado de realizar a festa; talvez por isso a substituição da rainha sorteada não tenha causado nenhum conflito aparente.

A rainha de 2010, sua neta, primou pela organização das atividades dentro da igreja, ornamentando-a e investindo para que, em todas as celebrações, houvesse a presença de um sacerdote, fato raro, uma vez que o povoado, ao longo do ano, só tem padre uma vez por mês e, durante a festa, um ou outro dia, incluído o da santa. Isso agradou os devotos que veem nas celebrações da igreja sua razão maior de participação. Nosso depoente abre sua casa para receber a folia de Sant'Ana, abriga os foliões e resgata a folia, que há algum tempo não acontecia por falta de quem a incentivasse. No terceiro ano de recorrência da folia, ela foi convidada a entrar na igreja no final da novena e a cantar seus versos com temas religiosos. Eis que o entrevistado, com sua família, alia de- 
voção, tradição e práticas católicas com o desejo de organizar o festejo, construindo, de certa forma, uma ação de domínio sobre o local não no sentido de imposição pela força; como Hatzfeld $(1993$, p. 63) argumenta sobre essa relação de autoridade que confia a "um chefe" a manutenção e a guarda da tradição, "há os que creem e os que duvidam. Há os que estão prontos a aquiescer e a seguir; e os que desconfiam ou não gostam de se pronunciar". Essa autoridade, que pode ser tanto aceita quanto replicada, se torna essencial para a vivência do sagrado e para a perpetuação da festa. Esses "guardiães da tradição", portadores da "verdade formular" (GIDDENS, 1997), na qualidade de pessoas que se envolvam diretamente, assumem as responsabilidades de organização da festa e detêm a autoridade e os poderes causais, sendo diferenciados dos demais membros da sociedade, conquanto revelam que a tradição se dá por "deferência" - sendo isto nitidamente caracterizado no papel desempenhado pelo entrevistado. ${ }^{5}$

O indivíduo sorteado para a festa de 2007 foi também festeiro em 2010. Essa repetição é pouco comum por causa da excessiva quantidade de nomes no sorteio. Ele é morador da vizinha cidade de Jaraguá, mas a família materna é da região do Tamanduá, situada no caminho entre Pirenópolis e a Capela do

5. Ao estudar a tradição cavalheiresca em Pirenópolis, Maia (2002) dá atenção especial aos "guardiães" na interpretação da função de alguns componentes $d a$ rede organizacional cavalheiresca e na manutenção da tradição dessa festividade.

Rio do Peixe, e cuja população também mantinha a tradição de ir à festa. Ao contrário do depoente anterior, cuja família é enorme e ficou vários anos na expectativa de ser sorteado, o festeiro de 2010 é solteiro e, no primeiro ano em que colocou o nome no sorteio, foi mordomo da luz elétrica, um dos cargos criados para auxiliar na realização. No ano seguinte, 2006, foi sorteado como festeiro e compôs a festa de 2007. Em 2009, foi novamente sorteado como festeiro e integrou a festa em 2010. No sorteio de 2010, coube a ele o posto de alferes da folia de Sant'Ana em 2011.

Sua família é pequena, constituída por pais, já idosos mas bastante atuantes nos afazeres do acampamento, irmã, tias e primas por parte de mãe. Em depoimento, após entregar a coroa para o festeiro de 2008 , disse estar feliz com a festa que realizara, tendo acontecido tudo o que pensara; segue, entretanto, dizendo: "infelizmente não dá para fazer tudo que se quer, mas graças a Deus realizei". 6 Percebemos, naquele mo6. Festeiro em 2007 e 2010. Entrevista realizada na Capela do Rio do Peixe mento, um tom de cansaço na voz do entrevistado e de incerteem 26.7.2009. za no tocante à satisfação popular com sua festa. Perguntamos, logo após o resultado do sorteio em 2009, qual a emoção de estar ali naquele momento. A resposta foi a seguinte:

a emoção é muito grande. É como eu disse... eu viria aqui e, se fosse da vontade de Deus, eu levaria a coroa. E, com muita alegria em meu coração, estou levando esta coroa pra casa e, a partir de amanhã, eu vou começar a trabalhar para esta festa para que esta festa aconteça em 2010. Há dois meses eu tive um sonho com essa festa, eu disse que eu ia ser festeiro desta festa em 2010, levantei, contei para minha mãe o sonho, fui ao trabalho com pressa, voltei, 
ela já estava deitada, sentei aos pés da cama dela e nós fizemos todo o relatório da festa. E hoje, pela graça de Deus, eu vou levar esta coroa, pela intersecção de Sant'Ana, eu vou levar esta coroa com muita alegria no meu coração e, em 2010, eu quero fazer essa festa como a outra no ano passado [2007].

O depoimento espontâneo concedido pelo festeiro recém-sorteado, ainda assustado com as coincidências, o sonho descrito e a crença nos desígnios divinos demonstram uma experiência viva, concreta e, num primeiro momento, individual, pois é fruto de sua relação particular com Deus, mas é também coletiva ao buscar o apoio na família para que a festa se realize como as anteriores. O novo festeiro deixa transparente a emoção do momento ao externar sua felicidade diante do fato de ter repetido uma experiência vivida há dois anos e que, com certeza, teve seus momentos difíceis, como o que registramos em 2007. Na sequência, o entrevistado conclama todos a compartilhar o momento: "em 2010, como muita alegria e com muita fé, eu quero estar aqui contando com a presença de todas as pessoas (...) aqui (...), todos os romeiros participando desta grandiosa festa de tradição e nos alegrando e louvando Sant'Ana, a avó de Jesus Cristo".

O momento só tem sentido para o indivíduo se for compartilhado com a coletividade, daí o convite extensivo a todos, a promessa do cumprimento da tradição e a garantia de que a festa repetir-se-á como sempre. Perguntamos a ele ainda qual o objetivo do partícipe ao entrar em tantos sorteios de festividades do catolicismo popular quando o comum é viver a experiência apenas uma vez. Segue a resposta. "é uma alegria grandiosa de trabalhar e ver que uma festa aconteça. Que as pessoas se sintam alegres, que as pessoas se enchem da presença de Deus, que as pessoas levam alguma coisa no coração, (...) principalmente o amor de Deus no coração".

\section{A FÉ QUE MOVE OS HOMENS}

Outra forma de participação característica das festas de santos do catolicismo popular é por meio do pagamento de promessas decorrente de votos feitos ao santo de devoção. Acompanhamos, durante três dias, a demonstração de fé de uma romeira de 75 anos de idade, nascida e criada nas proximidades do povoado da Capela do Rio do Pei$x e$, na fazenda denominada Carranca, localidade conhecida por todos da região. Acompanhamos a senhora no giro da folia de Sant'Ana, e sua promessa consistia em carregar a bandeira da folia nos três dias de giro pelos acampamentos, em visível sacrifício de fé não só pelas distâncias percorridas, mas principalmente pelo horário, pois, essa folia gira durante o dia, momento de sol forte, período de seca e de baixa umidade no cerrado. Entrevistamos a devota na chegada da folia ao acampamento do festeiro, etapa final do ritual, para a entrega da bandeira e dos donativos arrecadados nos três dias de giro. Conduzindo a bandeira em direção ao altar de Sant'Ana, a romeira deu um suspiro profundo e balbuciou "graças a Deus". Então perguntamos se considerava cumprida a promessa que fizera, e ela repetiu: "graças a Deus, muito bem cumprida". Inquirimos se o voto era somente para aquele ano ou se teria que se repetir sempre. Com uma risada, ela esclareceu: "a promessa é só este ano. Agora o ano que vem, se eu arrumar uma brechinha, eu vou de novo". Contou-nos então que participa da festa desde que nasceu, tendo sido ba- 
tizada ali e que seus pais "desde criança também frequentavam e pôs nós frequentando também, e eu estou pondo meus filhos também frequentando". ${ }^{7}$

Nessa forma de participação, nota-se que o envolvimento com as festividades é assaz denso, pois é resultado de uma série de fatores que dão sentido à ação e à tradição de se fazer presente todos os anos: é a fé manifestada na devoção e no pagamento de voto feito a Nossa Senhora Sant'Ana, é o vínculo com o espaço habitado e carregado de sentidos e as relações familiares ali constituídas que povoam a memória no presente. A despeito de morar na cidade de Pirenópolis, para essa depoente, o povoado e a festa da Capela representam o imago mundi, o lar, a hierofania e a sobreposição de histórias ali vivenciadas.

O retorno ao lugar de origem, de nascimento e vida é componente importante para se fazer presente na festa. Outro entrevistado, 66 anos de idade, nascido e criado em uma das pequenas fazendas que circundam o povoado da Capela do Rio do Peixe, hoje vivendo com a família na cidade de Pirenópolis, conhece desde pequeno o festejo e não deixa de comparecer ao local durante as festividades, mesmo não gozando de boa saúde. Fruto de uma promessa, o antigo morador organiza, há nove anos, um dos maiores grupos de caminhantes até a Capela no período que antecede a festa. E ele assim explica; "nós inventamos ela [a caminhada] com três pessoas. Aí nós pegamos pela fé e estamos fazendo essa caminhada aí". ${ }^{8}$ No início, nos três primeiros anos, era apenas para cumprir voto, então, convidou mais dois amigos e fizeram o trajeto, hoje o grupo exige uma organização, como presenciamos nos três anos que acompanhamos sua saída para a Capela. O grupo conta com aproximadamente 100 participantes, entre amigos, familiares e conhecidos que, em alguns casos, aproveitam o momento para também pagar suas promessas.

No discurso feito pelo organizador da caminhada diante de sua casa, onde todos se reúnem para a saída, ele pede companheirismo durante a caminhada, solicita três pessoas para ficar atrás do grupo a fim de se evitar a dispersão, chama a atenção dos participantes para ficarem atentos à bandeira, que não pode ser deixada sozinha e apela para a união de todos, lembrando que devem ir juntos, rezando o terço. Os caminhantes, com exceção dos que moram na Capela e participam da caminhada, retornam nos carros de apoio que acompanharam o grupo.

O companheirismo e a união cobrada pelo organizador são ratificações dos laços de amizade e parentesco que ele tem com os componentes do grupo. A emoção invade o entrevistado ao lembrar e nominar todos que estão na caminhada, os quais são citados pelos apelidos: "Zezinho Cabral, compadre Luiz, Zé Magno, Gilberto, Umberto, Tonhão Aquino, Marquinho..." E segue com a lista dos companheiros, alguns tidos como filhos, e seus familiares. Além de adultos e jovens, observamos a presença de várias crianças no 
grupo que, em regra, não são capazes de caminhar até o final do trajeto. E tanto os menores quanto quem não se sentir bem com o cansaço entram nos carros de apoio. Conta-se com pelo menos cinco carros pequenos, uma camionete com a comida e um caminhão com cobertura de lona e forrado com colchões para transportar os que se cansarem. São pelo menos 10 horas de caminhada até o destino, interrompidas para a degustação das comidas feitas para o momento - farofas de carne-seca (paçoca de pilão) e de frango, quitandas diversas, tais como biscoitos de queijo, pipocas (petas), bolachas, roscas, pães, frutas, refrigerantes, café e água.

Saindo da casa do organizador, ao som dos estouros dos fogos de artifício, o grupo ganha as ruas da cidade, formando uma procissão em cuja frente tem-se a bandeira, com a efígie de Sant'Ana com Maria, seguida pelo coro de fiéis com seus terços nas mãos rezando em voz alta. Por onde passam, chamam atenção, sendo comum as pessoas se colocarem à frente do grupo para beijar a bandeira. Finda a caminhada e após o retorno à casa, o grupo começa a preparar-se para voltar ao povoado, não mais como caminhantes, mas como romeiros, acampados para a festa.

O estar presente na festa dá-se de maneiras variadas e com diferentes graus de envolvimento. No primeiro ano da pesquisa, acompanhamos outro romeiro caminhante, de 76 anos de idade, que tem a tradição de fazer o percurso de $36 \mathrm{~km}$ até o povoado calçando sandálias tipo "havaianas" e em ritmo bem definido. Nós o vimos ultrapassar um grupo de aproximadamente 20 pessoas, entre jovens e adultos. Apresentando forte resistência e não demonstrando cansaço físico, o entrevistado contou que fez o percurso a pé muitas vezes - só de casado tinha 52 anos e desde solteiro realizava aquela caminhada noturna. O interessante é que o sacrifício não estava vinculado ao pagamento de promessas, mas à tradição de ir à festa e, contraditoriamente, de ir para o trabalho. Durante vários anos, informou, foi o responsável pelas obras de manutenção do prédio da igre-

9. Romeiro da festa da Capela. Entrevista realizada no povoado de Placas em 14.7.2007. ja e que, por isso, fazia o percurso do povoado até a cidade e vice-versa, algumas vezes desde o mês de junho, contratado pelos festeiros daquela época: "mexi de tudo quanto é lado naquela igreja". ${ }^{9}$ Desde então, ele continuou fazendo a caminhada para a Capela, hoje mais como uma reafirmação da fé professada.

Em nossa longa conversa falamos sobre a idade da festa e ouvimos: "ih, essa festa aí é antiga demais", "isso aí já é tradição antiga". E, sobre as mudanças por que a festa passou e que a fizeram diferente nos dias atuais, respondeu: "hoje é tudo com som, é diferente um pouco. Naquele tempo, chegava aí e era com sanfona, violão e pandeiro, só isso era um festão, só vendo. A festa boa tinha rancho". A fé era intensa, e ele não só já ouvira falar como, aliás, recebera graças de Sant'Ana.

Nas histórias individuais carregadas de complexidades desses três caminhantes distingue-se que "a consciência do passado é um elemento importante no amor pelo lugar" (TUAN, 1980, p. 114). As lembranças afloradas nos depoimentos demonstram a afetividade que os entrevistados têm para com o povoado da Capela. Outro fator recorrente é a peregrinação ao lugar sagrado, cujos referenciais ritualísticos são obtidos do catoli- 
cismo popular. É em tais práticas católicas que esses devotos buscam inspiração, tomando suas crenças e práticas como paradigmas para a construção de seus projetos de vida. O ritual de peregrinar até ou pelo povoado da Capela oferece aos devotos e participantes a oportunidade de trilhar um caminho espiritual por meio do deslocamento espacial.

Segundo Eliade, "cada ritual tem um modelo divino, um arquétipo" (1992, p. 29), é repetição da cosmologia, em que o "Centro é o âmbito do sagrado" (p. 26). A criação surgiu a partir de um centro, e o caminho até ele é difícil e perigoso, representando o ritual de passagem do profano ao sagrado - "nada pode durar se não for 'animado', se não receber uma 'alma', por intermédio de um sacrifício" (p. 28). Semelhante repetição do "ato cosmogônico", simbolizado e vivenciado no ritual, é que alimenta as devoções e cria o lugar. O sacrifício pela fé consagra o espaço em que o ritual se desenvolve, e por isso acreditamos que, para o devoto, o lugar da Capela do Rio do Peixe e de sua festa são espaços de devoção, e o dia de Sant'Ana é um período sagrado; em vista disso, a promessa só se cumprirá se houver o sacrifício, naquele lugar e naquele período. Isso diz respeito, de acordo com Relph (1980), à essência do lugar, porquanto os devotos se encontram profundamente envolvidos e têm forte identificação com ele; o lugar é "vivido", "dinâmico" e "carregado de significados".

\section{CONSIDERAÇÕES FINAIS}

A festa da Capela é o lugar da confluência de várias pessoas que compartilham por alguns dias maneiras diferentes de vivenciar a festa. Esse "lugar de encontros" está atrelado ao espaço e à paisagem, sendo estes partes imprescindíveis na constituição das identidades e nas manifestações do lugar. Esse lugar é, também, produto social, senão vários, resultante das redes de relações estabelecidas não só no dia do festejo propriamente dito, mas no período de preparação e no tempo do adormecimento, quando o lugar da festa é transportado para Pirenópolis. Entendemos, ainda, que a festa é um ponto de encontro de pessoas de temporalidades - é a evocação da memória individual e coletiva (HALBWACHS, 2004) - e escalas diferentes tornando-se um momento de numerosos contatos, de comunicação e de conflitos, um momento mais intenso do que qualquer outro do cotidiano. Assim, a festa em sua relação com o lugar tem o que Massey (2008) chamou de "sentido global do lugar", em que as diferentes e complexas relações se multiplicam no tempo e no espaço, multiplicando também os sentidos dados à festa. A celebração de Sant'Ana na Capela do Rio do Peixe reafirma os elos seculares e tradicionais entre os pirenopolinos e os defronta com sujeitos de épocas presentes e pretéritas, de modo a ampliar as teias das relações cotidianas.

Participar da festa não é meramente seguir os atos rituais, viver o momento festivo, mas é ter fé festejando, e para isso vive-se um período constituído por lugares determinados, situados espacial e espiritualmente, pois se realiza, de modo consciente ou não, um percurso interior. $E$, por ser um caminho, tem destino, de acordo com quem participa - ir ao encontro da santa, para render graças, estreitando as relações sagradas ou ressaltar os valores culturais do lugar, mantendo viva uma tradição familiar, reafirmando sua "internidade existencial" (RELPH, 1980). 
Evocando imagens e símbolos para as representações ritualísticas, os rituais alimentam um imaginário que confere sentido tanto à existência individual quanto à coletiva. Enquanto os partícipes da festa da Capela do Rio do Peixe, de forma individual e/ou coletiva, realizarem seus rituais em homenagem a Sant'Ana, buscando repetir o que os "Deuses fizeram no princípio", o festejo terá garantidas sua atualidade e sua durabilidade.

\section{REFERÊNCIAS BIBLIOGRÁFICAS}

ELIADE, Mircea. Mito do eterno retorno. Trad. José A. Ceschin. São Paulo: Mercuryo, 1992.

Tratados de história das religiões. 2. ed. Trad. Fernando Tomaz e Natália Nunes. São Paulo: Martins Fontes, 2002.

GEERTZ, Clifford. A interpretação das culturas. Rio de Janeiro: LTC, 1989.

GIDDENS, Anthony. A vida em uma sociedade pós-tradicional. In: BECK, Ulrich, GIDDENS, Anthony, LASH, Scott. Modernização reflexiva: política, tradição e estética na ordem social moderna. Trad. Magda Lopes. São Paulo: Universidade Estadual Paulista, 1997.

HALBWACHS, Maurice. A memória coletiva. Trad. Beatriz Sidou. São Paulo: Centauro, 2004.

HATZFELD, Henri. As raízes da religião: tradição - ritual - valores. Trad. Armando Pereira da Silva. Lisboa: Instituto Piaget, 1993.

HEIDEGGER, Martin. Ser e tempo. Trad. Márcia de Sá Cavalcanti Schuback. 4. ed. Petrópolis: Vozes, 2009.

MAIA, Carlos Eduardo S. Ritual e emoção nas interações espaciais - repensando o espaço sagrado nas festas populares de romarias e folguedos (notas introdutórias). In: ROSENDAHL, Zeny. Trilhas do sagrado. Rio de Janeiro: EdUERJ, 2010. p. 87-111.

MASSEY, Doreen B. Pelo espaço: uma nova política da espacialidade. Rio de Janeiro: Bertrand Brasil, 2008.

RELPH, Edward. Place and Placelessness. Londres: Pion, 1980.

ROSENDAHL, Zeni. O sagrado e o espaço. In: CASTRO, Iná Elias de; GOMES, Paulo César da Costa; CORRÊA, Roberto Lobato (orgs.). Explorações geográficas. Rio de Janeiro: Bertrand Brasil, 1997, p. 119-151.

TUAN, Yi-Fu. Topofilia: um estudo da percepção, atitudes e valores do meio ambiente. Trad. Lívia de Oliveira, São Paulo: Difel, 1980.

Tereza Caroline Lôbo é mestre e doutora em geografia pela Universidade Federal de Goiás e pesquisadora de festas populares.

Carlos Eduardo Santos Maia é doutor em geografia pela Universidade Federal do Rio de Janeiro e professor-associado I da Universidade Federal de Juiz de Fora. 